\title{
SISTEMA TRIBUTÁRIO E FEDERALISMO FISCAL ／ TAX SYSTEM AND FISCAL FEDERALISM
}

\author{
Fabiano Soares Gomes ${ }^{1}$
}

\begin{abstract}
Resumo
O presente artigo busca discutir a justiça do sistema tributário e as opções nessa perspectiva do federalismo fiscal. O artigo argumenta que houve uma profunda evolução em matéria de disciplina fiscal - através, dentre várias causas, de um progressivo abandono das teses de imposto único e concentração de esforços no aprimoramento de uma política de arrecadação financeira do estado. Uma política fiscal que contemple cada vez mais os princípios de justiça distributiva, de igualdade material, de eficiência, moralidade e impessoalidade estatais, além de uma maior racionalidade econômica que viabilize uma otimização da arrecadação com vistas à consecução das atividades-fim do estado.

No entanto, para se alcançar uma justiça fiscal há ainda um grande percurso à frente, especialmente no que se refere à criação de um contexto de viabilidade para uma reforma fiscal, especialmente para se evitar a deformação do texto constitucional através de sucessivos recortes por emendas constitucionais - muitas de duvidosa juridicidade - e a fragilização dos direitos que decorre de um tal comportamento.
\end{abstract}

Palavras-chave: Justiça fiscal. Tributação. Federalismo. Justiça distributiva. Igualdade material. Reforma fiscal. Constitucionalização de direitos.

\begin{abstract}
This article seeks to discuss the fairness of the tax system and the options that perspective of fiscal federalism. The article argues that there was a profound evolution in terms of fiscal discipline - through, among several causes of a progressive abandonment of the single tax theories and focus efforts on enhancing a policy of financial revenues of the state . A fiscal policy that includes increasing the principles of distributive justice, substantive equality, efficiency, morality and state impersonality, and greater economic rationality that makes possible an optimization of storage with a view to achieving the core activities of the state.

However, to achieve tax justice there is still a great journey ahead, especially as regards the creation of a context for the viability of a tax reform, especially to avoid deformation of the constitutional text through successive cuttings by constitutional amendments - many of dubious legality - and the weakening of the rights arising from such behavior.
\end{abstract}

Keywords: Tax Justice. Taxation. Federalism. Distributive justice. Material equality. Tax reform. Constitutionalization of rights.

\footnotetext{
${ }^{1}$ Mestre em Direito Público pela UERJ. Advogado no Rio de Janeiro.
} 


\section{INTRODUÇÃO}

No curso da história, diversas foram as formas com que se concebeu o estado e os alcances de suas atividades. Nessa perspectiva, RICARDO LOBO TORRES tece interessantes e precisas considerações sobre a evolução histórica da concepção de Estado, e, conseqüentemente, dos mecanismos de que se valeu para se sustentar e financiar suas atividades. Nesse sentido, desenvolve e defende a idéia de que com o fim da ordem bipolar, no início dos anos 90, fortalece-se o Estado Democrático e Social Fiscal, que mantém “características do Estado Social, mas passa por modificações importantes, como a diminuição do seu tamanho e a restrição ao seu intervencionismo no domínio social e econômico" ${ }^{2}$.

Neste modelo de estado, em que se identifica cada vez mais uma aproximação ao modelo subsidiário preconizado pela Doutrina Social da Igreja ${ }^{3}$, há a manutenção de características do estado de bem-estar, porém incorporadas à lógica de mercado, verificando-se a atuação estatal ou indiretamente, através do intervencionismo regulatório, ou diretamente - especialmente nas atividades estratégicas ou de políticas redistributivas. Com efeito, não obstante cogite-se de inúmeras formas de financiamento estatal, na perspectiva do Estado Democrático e Social Fiscal o principal modo de patrocínio às atividades financeiras do estado são os ingressos tributários, vez que a redução do aparato estatal e do intervencionismo direto implica na redução de aporte de receitas patrimoniais e parafiscais, assim como o fundamento ideológico do estado não permite meios autoritários de arrecadação ${ }^{4}$.

Com isso, observou-se desde o fim do século XIX um profundo aprimoramento tanto

\footnotetext{
${ }^{2}$ TORRES, Ricardo Lobo. Curso de Direito Financeiro e Tributário, 12. a ed. Rio de Janeiro: Ed. Renovar, 2005 , p. 09.

${ }^{3}$ O "princípio da subsidiariedade", tal como pioneiramente descrito na Encíclica Rerum Novarum (1891), do Papa Leão XIII, como bem ilustra a origem da expressão "subsidiariedade" (do latim subsidium, que era a denominação das tropas auxiliares do exército romano), informa que ao estado incumbe sempre uma atuação subsidiária à sociedade, deste modo propondo uma forma de organização do estado e de relação estado-indivíduo profundamente distinta dos modelos de estados maximalistas, minimalistas ou mesmo os estados de bem-estar. O princípio da subsidiariedade foi aprofundado, posteriormente, na encíclica Quadragesimo Anno (1931), de Pio XI, na Mater et magistra (1961), de João XXIII, na Populorum progressio (1967) e na carta apostólica Octagesima adveniens (1971), ambas do Papa Paulo VI, e nas encíclicas Laborens exercens (1981), Sollicitudo rei socialis (1987) e Centesimus annus (1991), estas do Papa João Paulo II. 4
}

TORRES, Ricardo Lobo. Curso de Direito Financeiro e Tributário. 12. ' ed. Rio de Janeiro: Renovar, 2005, p. 09. 
das teorias econômicas, necessário para fazer frente aos desafios sociais e políticos que se impuseram (e ainda hoje se impõem), como do direito financeiro e das técnicas de captação de recursos para o estado. Como bem assentou Aliomar BALEEIRO, a organização do sistema fiscal em métodos racionais é sempre produto da História ao longo dos séculos ${ }^{4}$. Assim, pretende-se sempre, como que num impulso de retroalimentação, aprimorar os modelos de arrecadação para, de um lado, evitar a crescente evasão fiscal decorrente da ampliação da economia informal/marginal (cujos custos operacionais substancialmente mais baixos, decorrentes da pára-legalidade, tornam-se mais atraentes que a adesão ao mercado formal, sobretudo em tempos de crise econômica e dentro de um contexto de fiscalização estatal que é incapaz de atingir a legião de cidadãos adeptos de tal setor econômico), e, de outro, promover em maior quantidade e com mais eficiência e qualidade a prestação de serviços públicos (vez que a atividade financeira do estado não é finalística, mas instrumental).

Destarte, muitos esforços têm sido empreendidos no sentido de se aproximar de um método de "arrecadação ideal", e, dentre dois modelos cogitados (ambas imbuídas igualmente de um utopismo idealista), vislumbram-se as teses do "imposto único" e de sistema tributário. Antes de se adentrar propriamente na seara do imposto único e do sistema tributário, vale trazer a ponderação do professor RICARDO LOBO TORRES a propósito de um idealismo fiscal:

\begin{abstract}
A possibilidade de um sistema tributário ideal é utópica. No Brasil temos uma certa tendência para a utopia fiscal, com a defesa do imposto único ou de impostos ou contribuições indiretas e invisíveis (imposto sobre transações financeiras, contribuições sobre lucro e faturamento). A ciência moderna vem abandonando a pretensão de apresentar um sistema tributário ideal, para se concentrar na idealização ou otimização de alguns tributos (imposto de renda, imposto sobre valor acrescido) ou de certos princípios (progressividade, neutralidade), com a advertência de que o ótimo fiscal ou o melhor tributo possível é sempre o second best. ${ }^{5}$
\end{abstract}

Feita a ressalva acima, no sentido de se prevenir contra a utopia e, ao revés, partir da realidade num esforço e num desejo de assegurar maior justiça fiscal, sem prejuízo do custeio das atividades do estado, pode-se passar à análise das teorias do imposto único e da sua antítese doutrinária, do sistema tributário.

BALEEIRO afirma que o problema da unidade ou unicidade dos impostos - ou seja, a

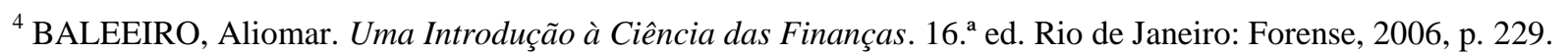

${ }^{5}$ TORRES, Ricardo Lobo. Curso de Direito Financeiro e Tributário. 12. ${ }^{a}$ ed. Rio de Janeiro: Renovar, 2005 , p. 359.
} 
intenção de se racionalizar a pluralidade tributária em um único imposto - remonta a Bodin, no século XVI, defensor de uma espécie de "imposto único sobre a renda", seguido no século XVII por Boisguillebert, Vauban, Colbert, Hobbes e Petty ${ }^{6}$. A tese ganha substância, contudo, somente com os fisiocratas, no séc. XVIII, que com Quesnay pretendeu-se tributar somente a renda líquida dos proprietários. "Assim, por economia e por justiça, todo o sistema fiscal deveria reduzir-se a um imposto único e direto até o máximo de 1/3 do produto líquido da terra, ou, mais exatamente, da renda que o proprietário recebe do agricultor ou criador que nela trabalha"7.

Defendida posteriormente por outros fisiocratas, a tese do imposto único só foi experimentada efetivamente nesta época uma única vez, com resultados contraproducentes. Contudo, serviu para a redução de tributos cobrados. A tese, no entanto, foi profundamente repudiada na época por personalidades como Adam Smith e Voltaire. No século XIX a idéia do imposto único reapareceu diversas vezes, sob formas diversas - por vezes como tributo incidente ao produto líquido da terra (fisiocratas), como imposto de consumo, como imposto sobre a renda, como imposto sobre a renda e a herança (Congresso Internacional do Imposto - Lausanne), como imposto sobre as fontes de energia (Echueller) ou como tributo incidente sobre o valor da terra (Henry George $)^{9}$. Em todo caso, como didaticamente explicita BALEEIRO, o imposto único traria as seguintes vantagens: a) simplicidade; b) economia na percepção; c) comodidade para os contribuintes; e d) consciência fiscal exata do montante pago. Por outro lado, salienta-se a utopia da tese no fato de que, para substituir-se à totalidade dos tributos cobrados, equiparando-se no volume de capital arrecadado, consistiria em uma carga tributária opressiva, que acabaria por aterrorizar o contribuinte, estimulando-o, contraditoriamente, à evasão, dissimulação e fraude ${ }^{8}$. Além disso, BALEEIRO aponta para o fenômeno da riqueza mobiliária, cujos montantes são fáceis de dissimular e de transferir, facilitando ainda mais a evasão e tornando absolutamente inócua a economia do imposto único, vez que os gastos com fiscalização e repressão cresceriam exponencialmente. Por fim, aponta-se a dificuldade em obter um único imposto que atingisse de forma eficaz e igualitária a todos, respeitando as diversidades particulares e a capacidade contributiva ${ }^{9}$.

Deste modo, o sistema tributário opõe-se ao imposto único, definindo-se como

\footnotetext{
${ }^{6}$ BALEEIRO, Aliomar. Uma Introdução à Ciência das Finanças. 16. ${ }^{\mathrm{a}}$ ed. Rio de Janeiro: Forense, 2006, p. 230.

${ }^{7}$ Ibidem, p. 230. 9

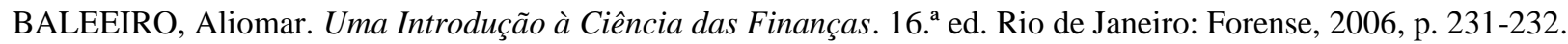

${ }^{8}$ Ibidem, p. 232.

${ }^{9}$ Ibidem, p. 233.
} 
tributações a vários títulos jurídicos - ou, de outro modo, pressupondo como ínsita à noção de sistema tributário a pluralidade de tributos -, com base em ato ou fato que indiquem riqueza ou capacidade contributiva, de forma a medir com idoneidade a força econômica de cada um para participar do custeio e da manutenção do estado, formando um conjunto econômico e organizado de exações/exigências financeiras. BALEEIRO destaca que

\begin{abstract}
O sistema tributário integra-se com os vários impostos que cada país adota, segundo o seu gênero de produção, a sua natureza geográfica, a sua forma política, as suas necessidades e ainda as suas tradições (...). Não é possível estabelecer-se cientificamente um sistema tributário padrão ou ideal para todos os países, nem para qualquer deles. Não se pode apagar o passado nem desprezar fatores políticos, morais, psicológicos e até religiosos. $\mathrm{Na}$ Constituinte de 1946, como na de 1934 e de 1891, o assunto foi apaixonadamente estudado e discutido. (...)

O sistema tributário deve ser produtivo, elástico, compatível com a renda nacional e com as idéias de justiça da época. Há de reservar competência nacional os impostos de base mais larga (renda, consumo, alfândega), Convirá evitar bitributação, de sorte que o mesmo imposto não venha a ser reclamado da mesma pessoa, e pelo mesmo fato, simultaneamente pela União, Estados e Municípios. ${ }^{10}$
\end{abstract}

De forma análoga, conclui José Marcos Domingues que

Superada a utopia do imposto único, a Economia, a Ciência das Finanças e o Direito conceberam os sistemas tributários como a solução a um tempo lógica e justa para o financiamento das necessidades públicas com respeito à princípio cardeal de Igualdade, de sorte que cada qual acuda ao chamamento estatal em função não só das exigências do Bem Comum, mas também tendo em vista a possibilidade do destinatário da ação estatal. ${ }^{13}$

\title{
2. SISTEMA TRIBUTÁRIO
}

Há vários atos da vida civil e da vida comercial que indicam riqueza, seja ela auferida ou adquirida, acumulada ou consumida, conforme a conceituação de Adolph Wagner. Com vistas ao financiamento do estado para a consecução de seus objetivos constitucionais (manutenção da segurança, prestação de serviços públicos, regulação do mercado, investimentos, realização de políticas públicas, dentre outros), estrutura-se um sistema tributário que atinge em maior parte as pessoas que praticam o maior número de atos desse gênero. Conclui-se que estas, por revelarem maior capacidade contributiva, estão em melhores condições de aportar recursos ao estado -

${ }^{10}$ Ibidem, p. 233.13

DOMINGUES, José Marcos. Direitos Fundamentais, Federalismo Fiscal e Emendas Constitucionais Tributárias. In: Revista da Faculdade de Direito de Campos, ano IV/V, n. ${ }^{\circ}$ 4/5, 2003-2004, p. 198-199. 
vedando-se, no entanto, o confisco, considerado ilegítimo por representar um extravasamento no poder do estado de interferir na propriedade privada. O sistema tributário, desta forma, está vinculado à riqueza nacional, podendo ser conceituado como o conjunto de exações, a vários títulos jurídicos, em face de situações ou atos que revelem capacidade contributiva, como expressão do princípio da igualdade.

Os sistemas tributários, todos inteiramente radicados na Constituição, podem ser identificados ou classificados, na visão de RICARDO LOBO TORRES ${ }^{11}$, como sistema tributário nacional, sistema tributário federado (ou sistema do federalismo fiscal) e sistema internacional tributário. Tal classificação obedece respectivamente os critérios de "base econômica de incidência", da "distribuição do poder de tributar" e, por fim, de "participação na riqueza internacional". O autor aponta, ainda, que os sistemas tributários poderiam ser classificados, do ponto de vista estrutural, como sistemas objetivos ou científicos ${ }^{12}$, sem que tal classificação, contudo, represente a nosso ver grandes ganhos didáticos ou doutrinários.

No entanto, a pluralidade e coexistência de diversos sistemas tributários - por mais que não se tratem de sistemas independentes, mas constituam por vezes faces distintas de um mesmo fenômeno $^{13}$ - impõe uma série de desafios na gestão financeira do estado, especialmente com vistas à coordenação de elementos que nem sempre se harmonizam como esperado ou desejado. Tal descompasso é bem descrito por RICARDO LOBO TORRES, que destaca que

Essa multiplicidade de aspectos do sistema tributário, com a necessidade de coerência e de harmonia entre os diversos subsistemas, é que tornam tão problemáticas as reformas fiscais e as revisões da Constituição Tributária. Combinar a maior racionalidade econômica possível, característica de um bom sistema tributário nacional ou internacional, com a maior autonomia dos entes públicos titulares da competência impositiva, marca de um sólido sistema tributário federado - eis aí o desafio permanente à criatividade jurídica. ${ }^{17}$

\subsection{Sistema Tributário Nacional}

O sistema tributário nacional é, conforme define RICARDO LOBO TORRES, “o que se

\footnotetext{
${ }^{11}$ TORRES, Ricardo Lobo. Curso de Direito Financeiro e Tributário. 12. ${ }^{\text {a }}$ ed. Rio de Janeiro: Renovar, 2005, p. 356.

${ }^{12}$ Ibidem, p. 356-357.

${ }^{13}$ Ibidem, p. 356.17

TORRES, Ricardo Lobo. Curso de Direito Financeiro e Tributário. 12. a ed. Rio de Janeiro: Renovar, 2005 , p. 356.
} 
estrutura de acordo com a base econômica da incidência, independentemente de considerações sobre a pessoa jurídica titular da competência impositiva" ${ }^{14}$. Encontra-se inscrito no texto constitucional nos arts. 145, 148 e 149 - que tratam da instituição de impostos, taxas e contribuições de melhoria, de empréstimos compulsórios e de contribuições sociais, econômicas e profissionais -, e no Código Tributário Nacional. Assim, compreende os tributos cobrados em todo o território nacional, "independentemente da titularidade deste ou daquele ente público e considerada exclusivamente a incidência sobre a riqueza" ${ }^{\prime 15}$.

Dentre suas principais características ${ }^{16}$, sobrelevam-se a racionalidade econômica, vez que previne superposições de incidência sobre fatos econômicos idênticos e o atrelamento a critérios jurídico-formais ou à técnica de arrecadação, por diferenciar com maior precisão os substratos econômicos, e a facilidade de arrecadação e fiscalização, minimizando custos operacionais e evitando perdas financeiras através da evasão fiscal.

Sua classificação é aquela adotada pelo Código Tributário Nacional (que seguiu o critério da EC n. ${ }^{\circ}$ 18/65), que distinguem, em relação aos impostos, entre aqueles que incidem sobre o patrimônio e a renda (IR, IPTU, IPVA, ITR, ITBI, I. causa mortir e doação e imposto sobre grandes fortunas) e sobre a produção e circulação (ICMS, IPI, IOF e ISS), em relação às taxas (art. 77 do CTN), de serviço ou de polícia, e, em relação às contribuições, de melhoria sociais - para a seguridade social e para a educação e cultura -, de intervenção no domínio econômico, de interesse de categorias profissionais, de interesses de categorias econômicas (contribuição sindical). Por fim, há ainda os empréstimos compulsórios ${ }^{17}$.

\subsection{Sistema Tributário Federal (ou Federalismo Fiscal)}

O sistema tributário federal pressupõe, preliminarmente, a existência de uma Federação de Estados, lastreando-se, com isso, na dotação de receitas tributárias entre os entes federados através da outorga direta de competência tributária, ou, então, através da partilha de receita tributária ou da utilização de fundos de participação. Para RICARDO LOBO TORRES, o federalismo fiscal pressupõe o "conjunto de tributos organizado segundo a distribuição do poder tributário à

\footnotetext{
${ }^{14}$ Ibidem, p. 357.

${ }^{15}$ Ibidem, p. 356.

${ }^{16}$ Ibidem, p. 357-358.

${ }^{17}$ Ibidem, p. 358.
} 
União, aos Estados-membros e aos Municípios" ${ }^{18}$. Desse modo, estrutura-se "a partir da consideração da pessoa jurídica titular da competência impositiva"23. Dentre seus pontos positivos, o federalismo fiscal permite a equidade entre os entes públicos - fundada numa isonomia federativa substancial, ou seja, de tratamento proporcional entre receitas e despesas de cada ente federativo -, assim como a autonomia dos Estados e Municípios para legislar e administrar os tributos de sua competência. Assim, com relação à separação do poder tributário - característica precípua do federalismo fiscal -, o tributarista assenta que

A sistematização dos tributos no federalismo fiscal tem, do ponto de vista jurídico, o objetivo de proceder à separação e à pulverização do poder tributário. Em face de sua extraordinária aptidão para destruir a liberdade, o poder tributário já nasce rigidamente limitado pela Constituição, sendo a partilha da receita um dos instrumentos mais eficientes para a garantia dos direitos fundamentais. ${ }^{19}$

Entretanto, ALIOMAR BALEEIRO aponta para uma dificuldade particular dos sistemas federados, qual seja o de que não só um, mas três entes devem alimentar-se dos tributos ${ }^{25}$. Além disso, ao analisar o federalismo fiscal, mister se faz tecer algumas considerações, com vistas ao correto entendimento tanto de seus elementos constitutivos, como de eventuais distorções que possam vir a ocorrer. Primeiramente, um fato que se evidencia na observação das experiências federativas é a de que não existe uma forma monolítica e acabada de federação. Sem embargo das formas anômalas modernas (como parecem se encaminhar as vertentes comunitárias), verifica-se nas federações o traço comum da existência de um ente central, que condivide parcela do poder soberano com os Estados-membros, político-administrativamente autônomos ao ente central. Nas palavras de LUÍS ROBERTO BARROSO, “a forma federativa de Estado procura conciliar o respeito à diversidade de cada entidade política com elementos de unidade indispensáveis à preservação da soberania e da integridade nacionais" ${ }^{20}$. A seu turno, a Federação pressupõe três elementos fundamentais, quais sejam, sinteticamente:

a) a repartição de competências, por via da qual cada entidade integrante da Federação receba competências políticas exercitáveis por direito próprio, freqüentemente classificadas

\footnotetext{
${ }^{18}$ TORRES, Ricardo Lobo. Curso de Direito Financeiro e Tributário. 12. a ed. Rio de Janeiro: Renovar, 2005, p. 357.

${ }^{23}$ Ibidem, p. 359.

${ }^{19}$ Ibidem, p. 359-360. 25

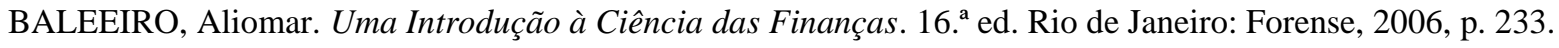

${ }^{20}$ BARROSO, Luís Roberto. Curso de Direito Constitucional Contemporâneo: os conceitos fundamentais e a construção do novo modelo. São Paulo: Saraiva, 2009, p. 171.
} 
em político-administraivas, legislativas e tributárias; b) a autonomia de cada ente, descrita classicamente como o poder de auto-determinação exercido dentro de um círculo prétraçado pela Constituição, que assegura a cada ente estatal poder de auto-organização, autogoverno e auto-administração; e c) a participação na formação da vontade do ente global, do poder nacional, o que tradicionalmente se dá pela composição paritária do Senado Federal, onde todos os Estados têm igual representação. ${ }^{21}$

No entanto, muito embora a federação pressuponha uma descentralização do governo em comparação aos estados unitários -, no sentido de preservar parcela de autonomia dos Estados a despeito da constituição de um ente central, há nítida diferença no grau de autonomia não só entre as diversas federações existentes até então, como também diferenças de grau no próprio desenvolvimento histórico-social das próprias federações. A este propósito, JORGE MIRANDA observa com propriedade que "o entendimento e a prática do federalismo não têm sido unívocos $e$ sem contrastes entre tendências centrífugas e centrípetas" ${ }^{\prime 22}$. Tais tendências referidas pelo ilustre constitucionalista português geralmente

Nesse sentido, a própria experiência federalista brasileira observou diversas oscilações no curso das diversas ordens constitucionais vigentes, traduzidas numa distribuição assimétrica de competências entre os entes, o que necessariamente produz reflexos na política fiscal, uma vez que ao ente que incumbir maior parcela de competências - especialmente as materiais -, mais recursos deverão ser dotados a este ente. A isso se deve a afirmação de RICARDO LOBO TORRES de que

O Brasil tem convivido, durante todo o período republicano, com um federalismo fiscal pendular, que alterna épocas de centralização de recursos financeiros e poder nas mãos do Governo Federal com outras em que se privilegiam os entes menores, tudo a coincidir com as vicissitudes do autoritarismo político. As Constituições de 1891 e de 1946 adotaram o perfil descentralizador, enquanto as Cartas de 1937 e 1967/69 inclinaram-se pelo modelo de centralização financeira. A Constituição de 1988, até como reação ao regime autoritário de $1967 / 69$, sinalizou no sentido da descentralização (...). ${ }^{23}$

Como se observou, muito deste "federalismo fiscal pendular" deve-se às contingências históricas, sociais, políticas e econômicas de cada período. Tal fenômeno não é, contudo, exclusivo do federalismo brasileiro - pode-se observar algo semelhante, por exemplo, na experiência

\footnotetext{
${ }^{21}$ BARROSO, Luís Roberto. Curso de Direito Constitucional Contemporâneo: os conceitos fundamentais e a construção do novo modelo. São Paulo: Saraiva, 2009, p. 172.

${ }_{22}^{2}$ MIRANDA, Jorge. Manual de Direito Constitucional. 7. a ed. Coimbra: Coimbra Editora, 2003, t. I, p. 146.

${ }^{23}$ TORRES, Ricardo Lobo. Tratado de Direito Constitucional, Financeiro e Tributário, volume V: o orçamento na constituição. 2. ${ }^{\text {a }}$ ed. Rio de Janeiro: Renovar, 2000, p. 297-298.
} 
norteamericana, em que houve profunda alteração nas formas de atuação e financiamento estatal dos entes federais na Era Lochner, no New Deal e na atualidade.

Há, portanto, pela própria natureza do modelo de estado federado, uma ínsita relação entre a distribuição de competências e a dotação de recursos, pelo simples fato de que a consecução dos mandamentos constitucionais impõe uma maior alocação de recursos a um ou outro ente da Federação. Com efeito, no caso brasileiro a Constituição atribui à União Federal, como a guardiã dos interesses nacionais, impostos com base de cálculo mais ampla (gerando maior arrecadação) como é o caso do IR, do IPI e do IOF -, por ser este o ente encarregado de mais competências, como defesa nacional, política externa, custeio da polícia federal, formulação, fiscalização e implementação da política econômica, investimento em obras de infra-estrutura e intervenção direta na economia, dentre outros exemplos. Já em relação aos Estados, o imposto mais importante é o ICMS, e em relação aos Municípios pode ser ou o ISS (como é o caso de Rio de Janeiro e São Paulo) ou o IPTU. Portanto, um dos objetivos do sistema tributário no federalismo fiscal é servir de instrumento à realização da democracia financeira e política ${ }^{24}$ entre os entes da federação e entre estes e os contribuintes. O sistema tributário, pois, deve ser compatível com a riqueza nacional e individual, e, neste particular, deve corresponder e ser proporcional à capacidade contributiva dos cidadãos.

Deste modo, a Constituição estabelece, em seus arts. 24, I, e 30, III, a competência concorrente da União, dos Estados, do Distrito Federal e dos Municípios para legislar sobre direito tributário. No entanto, RICARDO LOBO TORRES distingue, ainda, a separação do poder tributário em vertical e horizontal ${ }^{25}$. O primeiro, da separação vertical, corresponde à partilha do poder entre os entes federativos, levando àquilo que o autor vai denominar de "tridimensionalismo vertical" - vez que União, Estados e Municípios gozam de autonomia político-administrativa. A separação vertical, numa perspectiva moderna, estaria traduzida na integração vertical de competências. O segundo, da separação horizontal, compreende o poder de legislar sobre tributos, administrá-los e julgá-los. O poder legislativo é o único das três vertentes de separação horizontal que encontra explícito assento constitucional (arts. 145 a 156, c/c arts. 48 a 52, CF), sendo que o poder administrativo é correlato a este, ou seja, compete à pessoa jurídica que tem competência para instituí-lo (art. 6. ${ }^{\circ}$ do CTN), mas

\footnotetext{
${ }^{24}$ DOMINGUES, José Marcos. Direitos Fundamentais, Federalismo Fiscal e Emendas Constitucionais Tributárias. In: Revista da Faculdade de Direito de Campos, ano IV/V, n. ${ }^{\circ}$ 4/5, 2003-2004, p. 200.

${ }^{25}$ TORRES, Ricardo Lobo. Curso de Direito Financeiro e Tributário. 12. ${ }^{\mathrm{a}}$ ed. Rio de Janeiro: Renovar, $2005, \mathrm{p}$. 360361 .
} 
que pode, contudo, delegá-lo (art. 7. ${ }^{\circ}$ do CTN). O poder de julgar litígios tributários deriva da autoridade judicante genérica do art. 102 e seguintes da Constituição, mas reside especialmente no poder do judiciário de declarar a inconstitucionalidade (e a constitucionalidade, no caso dos tributos de questionável instituição) das leis - neste particular é curiosa a observação de que a Constituição alemã prevê explicitamente o controle judicial financeiro (art. 108, § 6. ${ }^{\circ}$ ). Por oportuno, vale breve menção ao caso norte-americano, que admite que o Judiciário, em situações excepcionais, determine a instituição de tributo pelo poder competente ${ }^{26}$.

Assim, analisando-se esquematicamente o poder tributário na sua divisão vertical e horizontal, cabe à União legislar privativamente sobre seus impostos (art. 145, I, c/c art. 153 e 154, todos da CF), sobre taxas e contribuições de melhoria que lhe competirem (art. 145, II e III, CF), sobre empréstimos compulsórios (art. 148 da CF) e sobre contribuições sociais e econômicas (art. 149 da CF). Em nível de uniformização e harmonia legislativa, cabe à União também legislar sobre os temas relacionados no art. 146 da CF. Em se tratando de poder legislativo, cabe ainda à União disciplinar as alíquotas de alguns tributos estaduais e municipais (art. 155, § 1. ${ }^{\circ}, \mathrm{IV}, \S 2 .^{\circ}, \mathrm{IV}$ e V, e art. 156, § 3. ${ }^{\circ}$, I, todos da $\mathrm{CF}$ ). Com relação à esfera administrativa, compete-lhe cuidar dos tributos que instituir, salvo a delegação expressamente prevista no art. 153, § 4. ${ }^{\circ}, \mathrm{CF}$. Quanto ao poder judicante, fica reservada a apreciação de litígios versando sobre seus próprios tributos, assim como aqueles dos Estados e Municípios que forem objeto de recurso especial ou extraordinário. Aos Estados cabe legislar sobre os impostos do art. 155 da CF (c/c art. 145, I, CF) e sobre as taxas e contribuições de melhoria a que alude o art. 145, II e III, CF. Cabe ainda aos Estados julgar os litígios decorrentes da aplicação de seus tributos, assim como dos tributos dos Municípios e do Distrito Federal. Aos Municípios, assim como ao Distrito Federal, cabe apenas o poder de legislar e administrar os seus impostos (art. 145, I, c/c art. 156, ambos da CF), taxas e contribuições de melhoria (art. 145, II e III, CF) e, se assim optar, fiscalizar e cobrar o ITR, de competência legislativa da União (art. 153, § 4. ${ }^{\circ}, \mathrm{CF}$ ).

Fica de todo evidente, ante o exposto, que as reflexões acerca do federalismo fiscal acabam por trazer a reboque, também, sérias considerações a respeito da maior ou menor autonomia dos entes federados, ou mesmo da existência real ou fictícia das federações. Isto porque não há como se falar em autonomia político-administrativa sem considerar a possibilidade de livre gestão

\footnotetext{
${ }^{26}$ A decisão pioneira na jurisprudência americana neste sentido foi Hutto v. Finney (437 US 678), julgado em 23 de junho de 1978 pela Corte de Apelações do oitavo circuito.
}

Revista Quaestio luris, vol.04, no01. ISSN 1516-0351 p.824-841 834 
de recursos, que precisam, por óbvio, existir. Mais que um mero impasse teórico, a autonomia financeira dos Estados é de importância topográfica nas Federações, tanto que em janeiro de 1788, Alexander Hamilton, por ocasião das discussões que levaram posteriormente aos textos de $O$ Federalista, defendeu que

\begin{abstract}
Although I am of opinion that there would be no real danger of the consequences which seem to be apprehended to the State governments from a power in the Union to control them in the levies of money, because I am persuaded that the sense of the people, the extreme hazard of provoking the resentments of the State governments, and a conviction of the utility and necessity of local administrations for local purposes, would be a complete barrier against the oppressive use of such a power; yet I am willing here to allow, in its full extent, the justness of the reasoning which requires that the individual States should possess an independent and uncontrollable authority to raise their own revenues for the supply of their own wants. And making this concession, I affirm that (with the sole exception of duties on imports and exports) they would, under the plan of the convention, retain that authority in the most absolute and unqualified sense; and that an attempt on the part of the national government to abridge them in the exercise of it, would be a violent assumption of power, unwarranted by any article or clause of its Constitution.

An entire consolidation of the States into one complete national sovereignty would imply an entire subordination of the parts; and whatever powers might remain in them, would be altogether dependent on the general will. But as the plan of the convention aims only at a partial union or consolidation, the State governments would clearly retain all the rights of sovereignty which they before had, and which were not, by that act, exclusively delegated to the United States. ${ }^{27}$
\end{abstract}

Paralelamente à discussão da autonomia federativa através da outorga de competência tributária, outro aspecto de capital importância é que muitos dos entes federados não possuem, a despeito de poderem arrecadar e gerir autonomamente seus tributos, capacidade de arrecadação satisfatória. Como se sustentou, o sistema tributário é composto por uma tributação a vários títulos, que, contudo, pode não ser suficiente para promover uma autonomia local ou estadual, com atribuição do bem comum por todos os entes. É evidente, na realidade brasileira, que há diversos Municípios (quando não Estados) que não têm capacidade para serem entes federativos, de modo que há uma federação desigual. Por conta disto, uma outra modalidade de federalismo fiscal é a que advém de uma "solidariedade federativa", em que ou se partilha a receita tributária arrecadada por determinado ente, ou se prevê a utilização de "fundos de participação". Nesse sentido, não obstante os entes da federação serem politicamente autônomos, possuindo independência para instituir, fiscalizar e cobrar determinados tributos, o Constituinte ponderou, acertadamente, que em vista das desigualdades e particularidades regionais, num país de grandes dimensões, a mera atribuição de

\footnotetext{
${ }^{27}$ HAMILTON, Alexander; MADISON, James; JAY, John. The Federalist. Indianapolis: Hackett Publishing Company, 2005, p. 168-169 (federalist paper $n$. 32).
} 
autonomia fiscal não é suficiente, sendo necessária a solidariedade federativa - vale enfatizar que, não raramente, os fundos de participação são a única fonte de riqueza de alguns Municípios brasileiros.

Contudo, há aqui que se fazer apenas uma nota com relação às contribuições, num tal contexto de solidariedade federativa. Isto porque, embora tenham fato gerador próprio de impostos como o IPI e o ICMS, as contribuições não são repartidas entre os entes da Federação, em verdadeira afronta às premissas de um federalismo fiscal. É fato, contudo, que tal distorção ocorreu dentro de um contexto determinado - por um lado, o combate à inflação nos anos seguintes à promulgação da Constituição, e, por outro, a uma maior necessidade de recursos por parte da União, por conta de uma descentralização (a que originalmente constava da Carta de 1988) desfigurada por inúmeras emendas constitucionais ${ }^{28}$. Fora isto, há ainda o problema da prevalência de critérios políticos na distribuição de créditos tributários, conduzindo não só a disputas regionais acentuadas como implicando no desvirtuamento de determinados tributos. É o caso, por exemplo, dos critérios de incidência e "partilha" do ICMS em operações que destinem petróleo ou derivados a outros Estados (já com tratamento diferenciado no art. 155, $\S 2 .^{\circ}, \mathrm{X}, b, \mathrm{XII}, h, \S 4 .^{\circ}$, da $\mathrm{CF}$, pormenorizadamente tratados na LC n. ${ }^{\circ} 87 / 96$, com suas alterações posteriores), que vem sendo amplamente debatida em razão de eventual exploração de áreas petrolíferas do "pré-sal”. No entanto, como bem ressaltado por RICARDO LOBO TORRES

Parece que o verdadeiro equilíbrio no federalismo fiscal é inatingível, principalmente em virtude da exagerada concentração de receitas em favor da União, decorrente do excesso de intervencionismo estatal da exasperação da idéia de desenvolvimento econômico e da desequilibrada distribuição de responsabilidades pelo fornecimento dos serviços públicos. ${ }^{29}$

Por fim, uma última questão relacionada ao federalismo fiscal é a que diz respeito à possibilidade de modificação da estrutura de repartição de receitas entre os entes federativos. Se por um lado é certo que dificilmente haverá proposta de emenda constitucional para expressamente abolir a forma federativa de estado, por outro é igualmente certo que tal propósito - como se anunciou anteriormente - pode lograr-se por vias transversas. Assim, são de relevo as reflexões se emendas constitucionais que alterem a repartição de receitas, ou mesmo as que instituem

\footnotetext{
${ }^{28}$ TORRES, Ricardo Lobo. Tratado de Direito Constitucional, Financeiro e Tributário, volume V: o orçamento na constituição. 2. a ed. Rio de Janeiro: Renovar, 2000, p. 299-300.

${ }^{29}$ TORRES, Ricardo Lobo. Curso de Direito Financeiro e Tributário. 12. ${ }^{\text {a }}$ ed. Rio de Janeiro: Renovar, 2005 , p. 364.
} 
contribuições que somente são aproveitadas por um dos entes federativos, não esbarram no impedimento do art. $60, \S 4$. $^{\circ}$, da Constituição Federal.

A este propósito, José MARCOS DoMINGUES destaca que há uma evidente conexão entre os fundamentos da República, consignados no art. 1. ${ }^{\circ}$ da Constituição Federal, e as cláusulas pétreas do art. 60 da Carta, assim como a forma federativa de estado e os direitos individuais e coletivos (art. 60, $\S 4 .^{\circ}$, I e IV, da CF), no qual estaria inserido o Federalismo Fiscal ${ }^{30}$. Mais adiante, o autor corrobora seu argumento de que as sucessivas emendas constitucionais em matéria financeira violam frontalmente, ilegalmente e imoralmente a ordem constitucional, tal qual resguardada materialmente pelo Constituinte Originário em cláusula Pétrea, consignando que:

Finalmente a cláusula pétrea dos direitos e garantias individuais garante a perenidade da Declaração de Direitos (sintomaticamente encimada pelo direito à vida, à liberdade, à igualdade, à segurança e à propriedade) cujas salvaguardas se espraiam pela Carta Magna, referenciando-se no particular o Direito Tributário pelo Título VI (da Tributação e do Orçamento, sobretudo o $\S 1^{\circ}$ do art. 145, art. 150, 151 e 152), sem prejuízo de outros, como o Título VII (da Ordem Econômica e Financeira) que contém inúmeras previsões principiológicas conexas à matéria, ex vi dos artigos 170 e $173 .{ }^{31}$

Quanto à Federação e ao Federalismo Fiscal - desde logo entenda-se que por emenda tendente a abolir a forma federativa de Estado devem-se considerar também aquelas que constranjam ou inviabilizem materialmente o exercício das tarefas dos entes federados, desde a União até o Município, da mesma forma como, em paralelo, se considera materialmente ilegítima uma lei que institua uma tributação confiscatória, aquela que por sua pressão fiscal exacerbada, grava o mínimo existencial, impede o exercício de atividade lícita ou aniquila a empresa. ${ }^{32}$

Em consequiência o que vê hoje e se projeta para o futuro próximo é a pauperização dos entes locais e o progressivo absenteísmo das instâncias estaduais e municipais nas áreas fundamentais ao exercício da cidadania e ao gozo da dignidade humana, quais sejam, educação, saúde e infraestrutura de saneamento e transportes, e o correspondente desestímulo ao investimento privado: e tudo isso substituído pela exclusão, marginalização e favelização, e pelo crime organizado. ${ }^{39}$

No caso das Emendas Tributárias têm elas se cingido a concentrar recursos na União Federal, violando o projeto constitucional de 1988 de descentralização democrática do Poder Político, em evidente contradição com o pacto federativo então concebido, ao mesmo tempo em que o faz através do estratagema da manipulação direta dos elementos essenciais dos tributos (base de cálculo e alíquotas de impostos e contribuições), em clara violação do princípio da Legalidade, para não falar no desrespeito superlativo à Separação de Poderes quando se pretende contrariar às escâncaras a Doutrina estabelecida pelo STF na sua função precípua de Guarda da Constituição, como se deu no caso da Contribuição de Iluminação Pública.

\footnotetext{
${ }^{30}$ DOMINGUES, José Marcos. Direitos Fundamentais, Federalismo Fiscal e Emendas Constitucionais Tributárias. In: Revista da Faculdade de Direito de Campos, ano IV/V, n. ${ }^{\circ}$ 4/5, 2003-2004, p. 198.

31 , p. 202-203.

${ }^{32}$ Ibidem, p. 203.39

DOMINGUES, José Marcos. Direitos Fundamentais, Federalismo Fiscal e Emendas Constitucionais Tributárias. In: Revista da Faculdade de Direito de Campos, ano IV/V, n. ${ }^{\circ}$ 4/5, 2003-2004, p. 206.
} 
Cabe ao Judiciário, e em especial ao STF, assumir uma atitude mais vigilante e ativa no controle de constitucionalidade das Emendas à Carta Magna, criando em seu favor melhores condições políticas que lhe ensejem o pleno exercício de sua Alta missão. ${ }^{33}$

\subsection{Sistema Tributário Internacional}

O sistema tributário internacional refere-se à gama de tributos incidentes sobre a riqueza internacional e que são repartidos entre os Estados soberanos conforme a disciplina constitucional (arts. 153, I e II, 155, $\S 1 .^{\circ}$, III, $b, \S 2 .^{\circ}, \mathrm{X}, a, 156, \S 3 .^{\circ}$, II), integrada e complementada pelos tratados e convenções internacionais (art. 98 do CTN) - como, por exemplo, convênios como os do MERCOSUL, GATT, ALCA, dentre outros, visceralmente importantes para a integração fiscal. Nesse sentido, o presente sistema serve ao regramento das relações para participação nas receitas decorrentes da "riqueza internacional", compreendendo as "incidências sobre o patrimônio, a renda e a circulação de bens referidos às relações entre cidadãos e empresas em diversos países ou, sob a perspectiva estatal, entende com a partilha da riqueza entre as diversas soberanias" ${ }^{21}$.

No que se refere à classificação do sistema tributário internacional, sustenta RICARDO LOBO TORRES $^{34}$ que se pode proceder segundo os mesmos critérios do sistema tributário nacional. Nesse sentido, há impostos que incidem sobre o comércio exterior - fundamentalmente o imposto de importação e o de exportação (art. 153, I e II, CF), além de eventualmente o IPI (art. 153, § 3. III, CF) e o ICMS (art. 155, § 2. $.^{\circ}, \mathrm{IX}, a, \mathrm{X}, a, \mathrm{XII}, f, \mathrm{CF}$ ), quando se tratar de relações comerciais internacionais - sobre o patrimônio e a renda - IR e imposto causa mortis, quando se tratarem de situações internacionais - e sobre a produção e a circulação - IPI, ICMS, IOF e ISS, nas hipóteses cabíveis.

\section{REPARTIÇÃO DAS RECEITAS TRIBUTÁRIAS}

$\mathrm{Na}$ esteira do que se sustentou anteriormente (cf. item 2.2), a repartição de receitas tributárias é um instrumento importante para o equilíbrio financeiro numa federação, desde que observe-se, por um lado, uma razoabilidade tanto na atribuição de quinhões como na justificação da partilha, e, por outro, meios precisos de controle para a entrega correta e pontual de recursos.

\footnotetext{
${ }^{33}$ Ibidem, p. 210.41

TORRES, Ricardo Lobo. Curso de Direito Financeiro e Tributário. 12. a ed. Rio de Janeiro: Renovar, 2005 , p. 364. ${ }^{34}$, p. 365 .
} 
Assim, conforme destaca RICARDO LOBO TORRES, as participações sobre a arrecadação é "instrumento financeiro, e não tributário, que cria para os entes políticos menores o direito a uma parcela da arrecadação do ente maior" ${ }^{35}$. Há ainda outras formas de auxílio financeiro a entes economicamente deficitários, como as subvenções, incentivos, créditos fiscais e auxílios a fundo perdido.

As participações podem ser diretas ou indiretas. A distinção reside fundamentalmente no fato de que as participações indiretas realizam-se através de "fundos de participação", sendo que a lei complementar pode estabelecer condições para o rateio. A seu turno, as participações diretas "são entregues diretamente aos entes menores ou por eles apropriadas mediante mera transferência

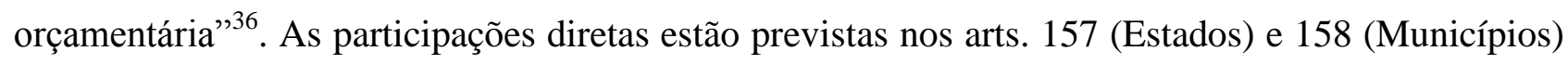
da Constituição, ao passo que as participações indiretas encontram-se previstas no art. 159 da CF fundos de participação em geral, fundo compensatório das exportações e CIDE do petróleo - e no art. 153, § 5. ${ }^{\circ}, \mathrm{CF}$ - participação dos Estados e Municípios na arrecadação do IOF. Há ainda as previsões dos arts. 76 e 91 do ADCT, que, respectivamente, prorrogou a Desvinculação de Receita da União (DRU) e previu a entrega futura de recursos para a compensação da imunidade do ICMS às exportações e dos créditos correspondentes às aquisições destinadas ao ativo permanente.

\section{CONCLUSÃO}

Por tudo quanto se expôs no presente trabalho, verifica-se que não obstante ter havido profunda evolução em matéria de disciplina fiscal - através, dentre várias causas, de um progressivo abandono (mesmo que não absoluto) às teses de imposto único e concentração de esforços no aprimoramento de uma política de arrecadação financeira do estado que contemple cada vez mais os princípios de justiça distributiva, de igualdade material, de eficiência, moralidade e impessoalidade estatais, além de uma maior racionalidade econômica que viabilize uma otimização da arrecadação com vistas à consecução das atividades-fim do estado. No entanto, há ainda um grande percurso à frente, especialmente no que se refere à criação de um contexto de viabilidade para uma reforma fiscal, especialmente para se evitar a deformação do texto constitucional através de sucessivos

\footnotetext{
${ }^{35}$ TORRES, Ricardo Lobo. Curso de Direito Financeiro e Tributário. 12. ed. Rio de Janeiro: Renovar, 2005 , p. 366. $36 \quad$, p. 367.
} 
retalhamentos por emendas constitucionais - muitas de duvidosa juridicidade - e a fragilização dos direitos que decorre de um tal comportamento.

Por fim, parece-nos igualmente na contramão da modernidade jurídica - de um Estado Democrático e Social Fiscal que pressuponha uma aproximação ao modelo subsidiário na esteira daquele preconizado pela Doutrina Social da Igreja - o reaparelhamento estatal que o Governo Federal vem fomentando nos últimos anos, que corresponde, necessariamente, a uma maior necessidade de ingressos públicos, ensejado o aumento da carga tributária que se tem testemunhado. Não há que se falar, entretanto, num esvaziamento que implique num retrocesso em políticas de cunho social que tenham se demonstrado exitosas - ainda que se admita o aperfeiçoamento de tais ganhos. O que se pretende, ao contrário, é evitar o excessivo gasto de verba pública em políticas que já demonstraram ser ultrapassadas e contraproducentes. De igual modo, há ainda muito que se empreender para modernizar a máquina pública e coibir práticas imorais, ineficientes ou de um paternalismo deletério, para que possamos viver, de fato, mais que numa "Era de Direitos", numa era de justiça, onde direitos e deveres coexistem, e todos vivem livres, com dignidade e plenamente.

\section{REFERÊNCIAS BIBLIOGRÁFICAS}

BALEEIRO, Aliomar. Uma Introdução à Ciência das Finanças. 16. a ed. Rio de Janeiro: Forense, 2006.

. Direito Tributário Brasileiro. 11. a ed. Rio de Janeiro: Forense, 2005.

BARROSO, Luís Roberto. Curso de Direito Constitucional Contemporâneo: os conceitos fundamentais e a construção do novo modelo. São Paulo: Saraiva, 2009.

DOMINGUES, José Marcos. Direitos Fundamentais, Federalismo Fiscal e Emendas Constitucionais Tributárias. In: Revista da Faculdade de Direito de Campos, ano IV/V, n. ${ }^{\circ}$ 4/5, 2003-2004, p. 197-211.

FALCÃO, Amílcar de Araújo. Introdução ao Direito Tributário. 5. a ed. Rio de Janeiro: Forense, 1994.

- Sistema Tributário Brasileiro: discriminação de rendas. Rio de Janeiro: Edições Financeiras S/A, 1965. 
HAMILTON, Alexander; MADISON, James; JAY, John. The Federalist. Indianapolis: Hackett Publishing Company, 2005.

MIRANDA, Jorge. Manual de Direito Constitucional. 7. a ed. Coimbra: Coimbra Editora, 2003, t. I.

TORRES, Ricardo Lobo. Curso de Direito Financeiro e Tributário. 12. ${ }^{a}$ ed. Rio de Janeiro: Renovar, 2005.

Tratado de Direito Constitucional, Financeiro e Tributário, volume V: o orçamento na constituição. 2. ${ }^{\mathrm{a}}$ ed. Rio de Janeiro: Renovar, 2000. 